\title{
NUEVOS CAMINOS PARA LA EDUCACIÓN ARTÍSTICA EN EL SALVADOR.
}

\author{
NOVOS CAMINHOS PARA A EDUCAÇÃO ARTÍSTICA NO EL SALVADOR.
}

NEW WAYS FOR ART EDUCATION IN EL SALVADOR.

\section{MARTA EUGENIA VALLE}

mevallecon@yahoo.com

Centro de Investigaciones en Ciencias y Humanidades, $\mathrm{CICH}$, Universidad Dr. José Matías

Delgado, El Salvador.

Basado en el documento "De lo cognitivo a lo espiritual en la Educación Artística: las competencias y los valores de las artes" presentado en el Foro Virtual del Congreso Iberoamericano, Beja, Portugal. Mayo, 2008.

Tipo de artículo: artículo original

\section{AGRADECIMIENTOS}

Agradecimientos a Milady Diana Casco de la Universidad de Austin, Texas por la asesoría científica en el artículo y a las personas entrevistadas por sus reflexiones.

\section{RESUMEN}

La Educación en El Salvador se encuentra en transición para responder a los retos que plantean los nuevos contextos globales, frente a ello, una de las medidas tomadas por el gobierno de El Salvador ha sido el diseño del Plan Nacional de Educación 2021. En lo que respecta al currículo nacional se han ajustado los programas al Modelo de Aprendizaje por Competencias (2009). Con relación a la educación artística, esta etapa puede ser una oportunidad para realizar la transición hacia un enfoque de la asignatura que cumpla su papel emancipador, como lo plantea Ana Mae Barbosa en el prefacio del libro Interdisciplinary Dialogues in Art Education, que lleve al educando hacia la construcción de un pensamiento crítico y creativo que a su vez le permita formular procesos para transformar su entorno (Barbosa, Ana Mae, 2008) ${ }^{1}$.

En este contexto educativo histórico, el artículo profundiza en las implicaciones de las competencias establecidas por el Ministerio de Educación en sus documentos. Para ello se retoman las visiones de dos autores: la perspectiva de las artes desde la Filosofía Perenne de Ángeles García Ranz, en su obra "El Artista Interior" (1999) y la visión desde la psicología Cognitiva de Rudolf Arheim, en su obra "Consideraciones sobre la Educación Artística" (1993); Dichas visiones se extrapolan a la Pedagogía Crítica y las consideraciones de Humberto Chávez Mayol

1 Barbosa, A M: ( 2008) Preface. In: Eça, Teresa. \& Mason, R. (Eds) ( 2008). Intercultural Dialogues in Art Education. London: Intellect Books. ISBN : 978-1-84150-167-3 
sobre la educación artística en los nuevos entornos globalizados, en la última parte, también se retoman las experiencias y reflexiones de estudiosos, educadores y gestores del país para analizar la funcionalidad de las artes en la actualidad.

\section{RESUMO}

A Educação em El Salvador encontra-se em transição para responder aos desafios que propõem os novos contextos globais, uma das medidas tomadas pelo governo de El Salvador foi o desenho do Plano Nacional de Educação 2021.

No currículo nacional o Ministério ajustou os programas ao Modelo de Aprendizagem por Compêtencias (2009), na educação artística, esta etapa poderia ser uma oportunidade se considera-se como uma transição para um enfoque da matéria que cumpra seu papel emancipador, como propõe Ana Mae Barbosa no prefácio do livro Interdisciplinary Dialogues in Art Education, que leve ao educando para a construção de um pensamento crítico e criativo que lhe permita formular processos para transformar seu meio (Barbosa, Ana Mae, , 2008).

Neste contexto educativo histórico, o artigo aprofunda nos envolvimentos das competências estabelecidas pelo Ministério de Educação em seus documentos. Para isso se retomam as visões de dois autores: perspectiva das artes desde a Filosofia Perenne de Ángeles García Ranz, em sua obra “O Artista Interior" (1999) e a visão desde a psicologia Cognitiva de Rudolf Arheim, em sua obra "Considerações sobre a Educação Artística" (1993); Ditas visões se extrapolan à Pedagogia Crítica, as considerações de Humberto Chávez Mayol sobre a educação artística nos novos meios globalizados e, na última parte, também se retomam as experiências e reflexões de estudiosos, educadores e gestores do país para analisar a funcionalidade das artes na actualidade.

\section{ABSTRACT}

Education in El Salvador is in transition to respond to de challenges of the new global contexts, consequently, the government of El Salvador, in addition to other actions has design the Plan Nacional de Educación 2021 (The National Plan of Education 2021). The Lesson Plans in the national curricula have been adjusted to the Competencies Based Learning (2009).This phase can be an opportunity for art education to start a transition focusing on emancipation, as stated by Ana Mae Barbosa in the preface for the book Interdisciplinary Dialogues in Art, and toward an art education that promotes the construction of critical and creative thinking that makes possible for the student to undertake processes for the transformation of his reality (Barbosa, Ana Mae, 2008).

In this historical educative context, this article explores the implications of the competencies stated by the government in the national curricula from the perspective of two authors : Ángeles García Ranz in her book El Artista Interior (The Artist Within, 1999) and Rudolph Arheim's vision from the Cognitive Psicology in his book "Consideraciones sobre la Educación Artística" (1993) (Thoughts on Art 
Education); both visions are extrapolated to the Critical Pedagogy and the considerations of Humberto Chavés Mayol concerning art education within the new global context, as well the author presents the experiences and reflections of academics, educators and promoters in El Salvador to analyzed the functionality of the arts today in the society.

PALABRAS CLAVE: educación artística, valores, intuición, percepción, expresión.

PALAVRAS CHAVE: educação artística, valores, intuição, percepção, expressão

KEY WORDS: Art Education, values, intuition, perception, expression.

\section{INTRODUCCIÓN}

En el marco de un ajuste curricular vigente a partir de este año², el Ministerio de Educación de El Salvador implementa el modelo de aprendizaje por competencias. En este ajuste, se mantienen en un $80 \%$ los contenidos de los programas anteriores y en educación artística se mantiene el enfoque disciplinar que a prevalecido en las últimas tres décadas, antes de esto, lo que se desarrollaba era una asignatura de manualidades, visión presente todavía en el desarrollo de la asignatura de educación artística en la enseñanza básica debido a la poca dinamización académica en el área, que obedece en gran parte, a la ausencia de programas para la formación de docentes especialistas en el país. Sin embargo la implementación en el currículo nacional del Modelo de Aprendizaje por Competencias en El Salvador y las medidas recientes que esta tomando el Ministerio de Educación para mejorar la formación de los docentes en Educación Artística, generan un espacio de oportunidad para considerar esta etapa como la transición hacia un enfoque de la asignatura de Educación Artística de acuerdo a las tendencias culturales y pedagógicas contemporáneas que se dirigen hacia una educación de las expresiones estéticas para la autonomía, el auto conocimiento, la construcción de la perso-

2 Al momento de ser publicada la presente versión de este artículo, ha habido cambio de gobierno en El Salvador (junio 2009), el actual gobierno esta realizando una revisión curricular de la cual se esperan cambios al Plan Nacional de Educación 2021, que fue el programa marco de la política de educación en el país desde el año 2004. Por lo que para el 2010, se prevé cambios curriculares que incidirán en la asignatura de educación artística. Por otra parte el ajuste de los programas del currículo nacional contemplado en el marco del Plan 2021 a penas entraron en vigencia en enero del 2009. nalidad, hacia el desarrollo de la capacidad reflexiva, el pensamiento crítico y pluralista, el diálogo multicultural y la emancipación por medio del placer del disfrute de las artes.

Por el momento el Ministerio de Educación (MINED) ha estipulado en los programas vigentes a partir del 2009, que las competencias en la asignatura de Educación Artística son: Percepción estética, Expresión estética e Interpretación de la Cultura y el Mundo Natural ${ }^{3}$. En este artículo se analizan las reflexiones que Rudolf Arheim ${ }^{4}$ (perspectiva cognitiva) y Ángeles García Ranz ${ }^{5}$ (Filosofía Perenne) hacen específicamente sobre estos tres aspectos contemplados en el currículo nacional salvadoreño, para presentar un abanico conceptual que se extrapola a la pedagogía crítica con relación a la educación artística. Para ello se discuten también la propuesta de Humberto Chávez Mayol (2007) ${ }^{6}$ y algunos conceptos de la pedagogía Fronteriza de Henry Giroux (2000)7 así como también se presentan experiencias y reflexiones de diferentes actores, artistas, docentes y estudiosos con relación a la

3 MINED, Programas de estudio de educación básica. http://www.mined.gob.sv/docentes/programas-estudio.asp. Consultado el 20 de abril de 2009.

4 Arheim, Rudolf. (1993), “Consideraciones sobre la Educación Artística": Ediciones Paidós.

5 García Ranz,Ángeles. (1999), El Artista Interior: De lo Espiritual en el Desarrollo Artístico: Editorial Piensa, S.A. de C.V.

6 Chávez Mayol,Humberto (2006), "Una Aproximación metodológica Interdisciplinaria en la Educación Artística":Cenidiap, Discurso Visual Revista digital Nueva Época, $\mathrm{N}^{\circ}$ 7, Septiembre-Diciembre 2006, $\mathrm{N}^{\circ} 7$, http://www.cenidiap.net, Consultado en Abril 2008.

7 Martínez, Luis González La Pedagogía Crítica de Henry A. Giroux. (Spanish), Sinéctica; ago2006-ene2007 Issue 29, p83-87, 5p. Article. http://search.ebscohost.com/login.aspx?direct=true $\& d b=z b h \& A N=25$ 325064\&amp;lang=es\&site=ehost-live. 
funcionalidad de las artes en los contextos actuales desde la realidad del país.

Bajo esa dinámica de análisis y debiendo replantear el sentido de la educación artística ante los actuales escenarios, este ensayo revisa los valores del arte y su vigencia, sumándose a la reflexión para contribuir a fundamentar la construcción de los nuevos proyectos educativos artísticos que contribuyan a la construcción social del país.

\section{El paradigma del arte, los nuevos contextos globales y algunos conceptos fundamentales para orientar la educación artística.}

“Desde mi punto de vista, el nuevo paradigma del arte es la conciencia de ambigüedad que bajo códigos múltiples se expande aleatoriamente en cualquier sentido." (Humberto Chávez Mayol, 2006). ${ }^{8}$

Esta frase de Chávez Mayol sintetiza el sentido que cobran las artes en los nuevos contextos que se caracterizan por cambios radicales, constantes, contradictorios y hasta perversos (Hargreaves, 1996, citado en Guzmán, 2003) ${ }^{9}$.

Por ello se hace necesaria la revisión del paradigma del arte con relación a la funcionalidad que las artes han cobrado en las sociedades contemporáneas y por consecuencia la revisión de la funcionalidad de la asignatura de Educación Artística, su enfoque y los valores que aporta al currículo nacional. En este ensayo interesa a la autora el planteamiento que explora la dimensión de las artes como dinamizadoras sociales y culturales (Chávez Mayol, 2007), un enfoque de la educación artística desde la pedagogía crítica ${ }^{10}$ y la pedagogía fronteriza (Giroux, 2000); visiones que dan origen a enfoques educativos artísticos que consideran el poder transformador de las personas sobre su propio entorno interno y externo por medio del

8 Chávez Mayol, Humberto, 2006, pp. Web no numerada, http://discursovisual.cenart.gob.mx/ nueva época $\mathrm{n}^{\circ} 7$.

9 J.C. Guzmán, Carlos Jesús. "Los Claroscuros de la Educación Basada en Competencias (EBC)”, p.149 Nueva Antropología. Revista de Ciencias Sociales Educación: perspectivas antropológicas Número 62 Abril Año 2003 ISSN 0185-0636. Consultado en http://www.juridicas.unam.mx/ publica/rev/indice.htm?r=nuant $\& \mathrm{n}=62$.

10 Henry Giroux, Michael Apple, Donaldo Macedo y otros. “conocimiento, las destrezas y los valores como contenidos educativos necesarios para que el alumno pueda negociar de manera crítica los límites culturales que le ofrece la sociedad $y$, en consecuencia para proceder a transformar el mundo en el que vive" (González Martínez, 2000) ${ }^{11}$. Perspectiva que reivindica el papel fundamental que la Educación Artística esta tomando en el currículo nacional de países en desarrollo, frente a posturas que niegan la necesidad de su existencia en el currículo por tratarse de contextos en donde predomina la pobreza.

Las competencias como modelo educativo, siendo un hecho de política educativa consumado en el país, deberían ser abordadas como herramientas que contribuyan a que, en la educación artística, los niños aprendan a observar, cuestionar, y adquieran consciencia sobre e intervengan su entorno.

Esta línea de pensamiento ha dado origen a las expresiones más recientes del arte contemporáneo. Por ejemplo, de este enfoque se derivan los proyectos artísticos que involucran a las comunidades y artistas, quienes en colaboración crean y recrean aspectos de su vida individual y comunitaria. Dichos proyectos contribuyen a cohesionar su individualidad y promueven el sentido comunitario ante los nuevos entornos y los retos de la sociedad del conocimiento y la globalización ${ }^{12}$.

Por otra parte se han abierto múltiples posibilidades que ofrecen la multidisciplinaridad y la transdisciplinaridad entre otras áreas del conocimiento y entre éstas y las artes, teniendo un impacto importante, dice Chávez Mayol, en el discurso artístico lo cual evidencia más que nunca la dimensión de las artes como: “... una maquinaria ficcionante relativa y ambigua que teje y desteje la esperanza de cambio, de renovación, de individualidad..." ${ }^{13}$ (Chávez Mayol, 2006).

11 Martínez, Luis González. La Pedagogía Crítica de Henry A. Giroux. Sinéctica; ago2006-ene2007 Issue 29, p83-87, 5p. http://search.ebscohost.com/login.aspx?direct=true $\& \mathrm{db}=\mathrm{zbh} \& \mathrm{AN}=25325064 \& \mathrm{amp}$;lang= es\&site=ehost-live. Consultado en abril de 2009.

12 Ver dos ejemplos en el país: http://lacapacidad.blogspot. com/2008/01/prefacio.html ; http://www.wallsofhope.org/es/escue-

13 Ibíd.. 
Este autor describe así la posibilidad que tienen las artes de romper la rigidez que inventa la cultura, en donde intermedia el artista y espectador para poner en marcha esa maquinaria: "por el incierto desplazamiento de un ingenio, de un talento, de una gracia, de una conciencia o de una fe" ${ }^{14}$ (Chávez Mayol, 2006).

Por lo tanto la fuerza del discurso artístico (ahora cada vez más multidisciplinario y transdisciplinario), en donde creador y espectador participan de manera cada vez más activa, - como en una especie de complicidad con el artista -, se renueva ante los escenarios globales. En estas nuevas realidades, en las cuales se tiende a aplanar las culturas y las identidades individuales y colectivas, el discurso artístico cobra nueva importancia como un medio para que los individuos y las colectividades se reencuentren con sus realidades (internas y externas), las interpreten y adquieran conciencia de ellas, para transformarlas.

Ser consciente, estar en contacto consigo mismo, con las realidades internas y externas son pasos importantes hacia la lucidez y también posibilitan la creación y la recreación del imaginario, como lo veremos más adelante en las explicaciones que R. Arheim y Ángeles García Ranz brindan sobre los procesos perceptivos y de expresión ${ }^{15}$.

En el desarrollo de las artes y la educación artística hoy, también tienen influencia en alguna medida los medios de información y sobre todo el virus de la saturación descrito por D. Moraes, ya que tiene un poderoso potencial de alienación porque: “... afecta la sensibilidad crítica, induciendo, sutilmente, al individualismo, a la dispersión y a la complacencia delante de injusticias sociales" ${ }^{16}$ (Moraes, 2004).

Pero también -si se quiere - los nuevos entornos y este flujo de información y sus implicaciones en los diversos campos disciplinarios, nos presentan un abanico sin pre-

14 Ibíd.

15 Rudolf Arheim, su libro Consideraciones sobre la Educación Artística (1993) y de Ángeles García Ranz, El Artista Interior: De lo Espiritual en el Desarrollo Artístico (1999)

16 Dênis de Moraes: La saturación mediática en el capitalismo neoliberal: http://firgoa.usc.es/drupal/node/6321, 2004. Consultado en Agosto 2008. cedente para la exploración de posibilidades, la reinvención individual y para contemplar, desear y pensar las posibilidades contextuales de cambio. Esto se potencia en la medida en que, en el continuo cotidiano, las personas y sus sociedades tienen la posibilidad de activar la dimensión de las artes como la "maquinaria" que teje la esperanza de cambio, como dice Chávez Mayol (2006) y la individualidad, ésa que dicho autor describe, en profunda relación con la dimensión colectiva de las sociedades, su cultura e historia.

Así, la visión del nuevo paradigma de las artes de Chávez Mayol junto con los aspectos fundamentales de la pedagogía crítica y pedagogía fronteriza de Giroux (2000) resultan una visión muy poderosa a considerar para el desarrollo de la educación artística en esta nueva fase que el Ministerio de Educación abre en el currículo nacional del país a partir de la entrada en vigencia de los programas de estudio, su desarrollo bajo el Modelo de Aprendizaje por Competencias y el proyecto de mejorar la formación en educación artística de los docentes en el país.

\section{Nuevos entornos y la competencia artística}

Como se ha dicho en El Salvador se ha adoptado, este año, en el currículo nacional el modelo de Aprendizaje por Competencias. La Educación Basada en Competencias (EBC) desde la década de los 70 ha estado sujeta a apologías y también ha recibido críticas internacionalmente, por ello se han generado mucho debate y propuestas. En el campo de la educación artística hay expresiones ante la EBC como por ejemplo, en el Congreso Iberoamericano de Educación Artística, en el sentido de que los modelos competencistas se pensaban superados (sesión de cierre, Beja, Portugal, 2008),

Por hoy la EBC esta vigente en varios países del mundo; en El Salvador el sistema educativo salvadoreño implementa la Enseñanza Basada en Competencias (2009), y a ello responden los programas actuales de la materia de Educación Artística, al igual que las competencias que el Ministerio de Educación determinó para la asignatura. 
Por ello, este ensayo se enmarca en la Enseñanza Basada en Competencias (EBC). Sin embargo, aquí se retoma en el marco de una propuesta que contempla la Educación para la vida ${ }^{17}$, como lo expresa el Ministerio de Educación en sus documentos. De tal manera, se entiende que la EBC que el MINED pretende implementar en el país se aleja de la tentación de tener como único referente para la definición de las competencias en la escuela, a las exigencias laborales de parte de las instancias empleadoras, paso histórico muy importante para la educación nacional.

Por lo tanto, desde ese planteamiento institucional, se espera que se promoverá desde el Estado, una visión flexible y dinámica de las competencias y dará énfasis en equilibrar el nivel de especificidad o generalidad, lo teórico y lo procedimental, tomando en cuenta las actitudes, el equilibrio entre las demandas de los entornos no laborales (familia, comunidad, sociedad, etc.), lo académico y los entornos de desempeño laborales, y dicho equilibrio sería el criterio para determinar la relevancia de las competencias que se enseñan en la escuela.

Por otra parte, los contextos globalizados confrontan la fase tecnológica energética que se encuentra pujante con una fase emergente que A. Hargraves (1996) describe como: inmaterial (símbolos, códigos, mensajes, organización) ${ }^{18}$. Esta confrontación ha generado demanda de una alta capacidad para solucionar problemas, manejo del cambio constante y de la incertidumbre ante la cantidad, variedad y la rápida obsolescencia de la información.

También se coincide en la necesidad de un perfil que incluya más habilidades para el pensamiento innovador, conciencia cultural, habilidades cognitivas de más alto nivel como el pensamiento crítico y habilidades de comunicación y colaboración más sofisticadas (Hardgraves, Guzmán, Orozco, Gardner).

Desde esta perspectiva se requiere de una metodología de la enseñanza de las artes que se acomode particularmente a la naturaleza cuestionadora y relativizante del

17 Ministerio de Educación de El Salvador, El Currículo al Servicio del Aprendizaje, 2007, p.6.

18 Hargraves, citado en Guzmán, 2003. arte para absorber las transformaciones culturales emergentes. ${ }^{19}$

Chávez Mayol (2006) lo describe así:

El discurso artístico, en la actualidad, es integrador. Puede unir los saberes de las diferentes expresiones artísticas pero también absorber conocimientos de cualquier campo de la cultura. Este proceso no sólo debe fundamentarse en la suma de saberes, informaciones y prácticas, sino que implica la creación de una propuesta teórico-metodológica que permita a los profesores, investigadores y alumnos comprender y participar en el nuevo panorama de competencia artística. ${ }^{20}$

En consecuencia Chávez Mayol propone un abordaje didáctico constructivo en respuesta a la naturaleza dinamizadora del pensamiento cultural que caracteriza hoy al arte y los nuevos entornos. Este abordaje lo resume en un metasistema formado por tres niveles que describe así: ... el primer nivel busca el encuentro de saberes, el segundo la maquinaria instrumental lógica que lo permita y el tercero la conciencia transformadora del sujeto que lo construya. Los niveles se fundamentan en tres aproximaciones teóricas de gran flexibilidad, cada una implicada consustancialmente en la propuesta de las otras: "El pensamiento complejo, las nuevas aproximaciones semióticas como sistema organizacional y la propuesta constructiva de enseñanza aprendizaje como modelo educativo de revitalización de valores" (Chávez Mayol, 2006). ${ }^{21}$

Por lo tanto, de acuerdo a las nuevas realidades, ante la implementación de los modelos educativos por competencias en el currículo nacional bajo el enfoque de "educación para la vida" desde una visión constructivista humanista, como se expresa en los documento del Ministerio de Educación, y de acuerdo a los nuevos paradigmas artísticos y las tendencias educativas, el Estado salvadoreño debería considerar orientar la formación de docentes en el país hacia la Pedagogía Crítica que lleve a una Pedagogía Fronteriza (Giroux, 2000) para propender a que la educación artística brinde experiencias signifi-

\footnotetext{
19 Ibíd.

20 Ibíd.
}

21 Ibíd. 
cativas de aprendizaje que contribuyan a que la niñez y la juventud en los centros educativos de El Salvador, entre otras cosas, tengan la oportunidad de desarrollar un pensamiento crítico y manejen habilidades cognitivas y estrategias que les permitan protagonismo e incidencia frente a las realidades que los rodean, además de tener acceso al placer del disfrute de las artes y contemplar en su imaginario la opción de una profesionalización en el campo de las artes como lo hacen al plantearse otras profesiones tradicionales que con más naturalidad son abordadas desde la escuela.

Esto debería traducirse en la educación artística del país en el marco para una didáctica de las artes que propenda situaciones de enseñanza aprendizaje que cree las condiciones para que los educandos:

Exploren de manera vivencial la dimensión dinamizadora de las artes, su potencial para enriquecer la vida y como un medio dinamizador social para la transformación y estructuración social.

Una didáctica de las artes que acomode las transformaciones culturales emergentes que plantean el arte contemporáneo y los nuevos contextos globales para contribuir a que los educandos construyan sentido y valores solidarios ciudadanos (derechos y deberes) con relación a estos nuevos entornos omnipresentes en sus vidas.

Que esta didáctica armonice el enfoque educativo constructivista con el modelo basado en competencias para la vida que tenga como base fundamental los derechos humanos y que se traduzca en conocimientos, destrezas y valores que contribuyan a la auto realización, la construcción ciudadana y social de una cultura de paz y el desarrollo sostenible.

Una lectura de los valores de las artes en el aprendizaje constructivo y por competencias en la asignatura de Educación Artística

E. Eisner, refiriéndose a la visión que todavía prevalecía a principios de los noventa en Estados Unidos con relación a la Educación Artística describe los enfoques tradicionales así: “...En resumen, nuestras teorías educativas, aun cuando sólo sean implícitas, consideran que las cuestiones de percepción están relacionadas con la sensación no inteligente y las cuestiones de creación con el simple uso de nuestras manos" (E. Eisner, 1993). ${ }^{22}$

Existen evidencias de que en El Salvador prevalece un enfoque parecido de la educación artística ${ }^{23}$.

¿Qué implicaciones tienen las competencias (Percepción estética, Expresión estética e Interpretación de la Cultura y el Mundo Natural) ${ }^{24}$ definidas por el Ministerio de Educación para la asignatura de Educación Artística en el currículo nacional? En un ambiente de transición, este artículo interpreta a continuación, las implicaciones conceptuales que dichas competencias tienen desde la visión de Rudolf Arheim en su libro Consideraciones sobre la Educación Artística ${ }^{25}$ (1993), la autora, Ángeles García Ranz, en su libro El artista interior ${ }^{26}$ (1999) y desde el enfoque de la pedagogía crítica.

En su obra Consideraciones sobre la Educación Artística (1993) $)^{27}$ Arheim enfatiza en las artes visuales, sin embargo generaliza sobre el sentido de las artes en sus diferentes lenguajes artísticos y en la educación de las personas desde una idea central y cuatro ideas implícitas siguientes ${ }^{28:}$

Idea central: que el arte nos acerca a nuestra humanidad.

Idea que Arheim desarrolla en su libro en las cuatro ideas implícitas siguientes

1- "...el sistema sensorial es uno de los principales recursos de nuestra vida cognitiva".

22 Eisner, Elliot citado en Arheim, Rudolf ,1993, p. 15

23 Valle, Marta Eugenia. La Educación Artística en la enseñanza básica en El Salvador. Se encuentra en preparación. CICH, Universidad Dr. José Matías Delgado. El Salvador, 2009.

24 MINED,Programas de estudio de educación básica. http://www. mined.gob.sv/docentes/programas-estudio.asp. Consultado el 20 de abril de 2009 .

25 Arheim, Rudolf. (1993), "Consideraciones sobre la Educación Artistica", Ediciones Paidós.

26 García Ranz, Ángeles. (1999), El Artista Interior: De lo Espiritual en el Desarrollo Artístico: Editorial Piensa, S.A. de C.V.

27 Arheim, Rudolf. (1993), “Consideraciones sobre la Educación Artistica", Ediciones Paidós.

28 Ibíd. p.15-19. 
2- "El desarrollo óptimo de la mente requiere atención no sólo a los procesos intelectuales sino también a los intuitivos".

3- La relación entre diferenciación y generalización: “Lo importante en las artes, en el fondo, no es sólo la generalización, sino la individuación".

4- "Que los medios (artísticos) revelan sus características únicas por contraste con otros medios".

Por su parte Ángeles García Ranz en su obra El Artista Interior (1999, p.9) revisa al arte desde la dimensión de lo espiritual, entendido no desde la perspectiva religiosa ${ }^{29}$ sino desde una especie de metaconciencia que ve al arte como una acción humana de carácter polifásico, desde el punto de vista antropológico.

Al mismo tiempo, García Ranz desde el marco de la filosofía perenne, propone la filosofía perenne del arte, profundizando sobre la intuición como forma de conocer

Al establecer un diálogo conceptual entre R. Arheim y García Ranz se puede hacer una propuesta de lectura de las competencias artística, que pretende explorar y profundizar en los valores fundamentales del arte que le dan sentido a la educación artística en el currículo para la formación de humanidad.

\section{Los valores del arte y las competencias educativas}

En su obra "El Artista Interior : de lo Espiritual en el Desarrollo Artístico" 23 (1999) Ángeles García Ranz brinda un enfoque desde lo espiritual de manera renovada, que se encuentra a un extremo del abanico de las posibilidades del análisis que representa una visión desde la filosofía perenne, que aquí se extrapola con el enfoque cognitivo del psicólogo R. Arheim, punto de vista que representaría el extremo opuesto, en un abanico virtual de lectura de las artes como un hecho de esencia humana. En dicho análisis se propone la posibilidad de pensar en un espacio interesante intermedio entre estas dos perspectivas, a

29 Para A.García Ranz lo espiritual se refiere a: El mundo que va más allá y de nuestra experiencia sensible, la cual forma parte íntima de la vida (1999, p.9). considerar en el campo conceptual con relación al desarrollo de la asignatura de educación artística.

Dicho espacio intermedio entre las dos perspectivas de análisis mencionadas, debería ser tomado por la pedagogía crítica, que frente a dichas visiones (espiritual y cognitiva), se constituye en la herramienta para proponer una pedagogía de las artes en la escuela que explore la intuición (García Ranz) y las estrategias cognitivas (Arheim) con un fin: el de promover la autoconciencia (metacognición) y el pensamiento crítico que lleve a los educandos a imaginar la transformación social.

Por ello, en el presente ensayo se aborda cómo la dimensión espiritual opera en la educación artística, en armonía con el enfoque cognitivo que parecería una dimensión contrapuesta a la primera; así también, se plantea que no son excluyentes con una pedagogía crítica en la Educación Artística que pretende promover procesos de autonomía que lleven a la emancipación de lo que impide la convivencia, el desarrollo humano y sostenible en nuestras sociedades.

De esta forma las artes y la educación artística se abordan aquí para revelar la riqueza de las implicaciones que tienen en la vida de las personas, porque este análisis no rehuye la subjetividad de la dimensión espiritual de las artes y sus coincidencias con el análisis cognitivo de carácter psicopedagógico, racional y lógico que propone R. Arheim desde la psicología cognitiva. Como también se propone que estos procesos individuales también son colectivos y llevan a la autonomía, autoconciencia y a la promoción del pensamiento crítico. Es así que el presente análisis plantea la cualidad de las artes y el potencial de la educación artística para crear una condición de aguzamiento hacia lo que forma parte de nuestra vida (entorno interior y exterior), su potencial para acercarnos a los demás y trasformar.

La intuición en las artes.

A la base de las competencias: percepción y expresión estética, interpretación de la cultura y el mundo natural, opera la intuición. Tanto Arheim como García Ranz nos describen las implicaciones que la intuición tiene con re- 
lación a la formación humana por medio de la educación artística.

Como se ha explicado, García Ranz propone desde el marco de la Filosofía Perenne, a la Filosofía Perenne del Arte cuyo marco conceptual da cabida a la intuición (forma de conocer holista) como manera distinta de conocer a la analítica (razón,lógica) tradicionalmente más confiable a las ciencias ${ }^{30}$ (García Ranz,1999).

Desde este marco García Ranz deriva la siguiente idea fundamental para la presente discusión: La fuente de todo arte verdadero es siempre la cognición intuitiva de la realidad. (García Ranz, 1999). ${ }^{31}$

Por su parte Rudolf Arheim con relación a la intuición dice: El desarrollo óptimo de la mente requiere atención no sólo a los procesos intelectuales sino también a los intuitivos (Arheim, 1993). ${ }^{32}$

Arheim explica que por medio de la intuición en la niñez se tiene la capacidad de aprehender coincidencias en los objetos que percibimos y con los que se interactúa, al estabilizarse estas percepciones intuitivas se generan los primeros conceptos intelectuales que constituyen conceptos intuitivos completamente perceptivos petrificados, se componen de conjuntos de rasgos estandarizados ${ }^{33}$. Sin embargo esta estandarización de conceptos tiene su precio, estos conceptos intelectuales carecen de: ...la preciosa conjunción de apariencia individual y generalización que hay en la naturaleza de los conceptos intuitivos. (Arheim, 1993) $^{34}$

Es así como ambos autores coinciden desde dos vertientes de análisis diferentes, en que la intuición es la herramienta que permite ese ver que lleva a trascender los primeros conceptos intuitivos petrificados hacia una visión más holística, para ir al encuentro de realidades más profundas y esenciales de lo que nos rodea. En el marco de la pedagogía crítica esta manera intuitiva de aprender

\footnotetext{
30 Ibid. pp. 18

31 Opcit. El Eisner citado en Arheim, 1999 pp.16

32 Arheim, 1993, pp

33 Ibid. pp50

34 Arheim, R. 1993,pp 50
}

a ver es una herramienta interesante para problematizar el conocimiento.

\section{Percepción e intuición}

Ángeles García Ranz profundiza en la intuición partiendo de la percepción. Plantea que la base fundamental de dicho proceso mental es la reflexión, en la filosofía del mundo occidental se evidencia en un movimiento pendular que ha oscilado entre la reflexión sobre la concepción del yo y la concepción del universo; en las filosofías orientales la reflexión se manifiesta en la meditación como elemento fundamental y refinado para conocer (García Ranz, p.17, 1999).

Es así como la percepción implica una dinámica de reflexión para conocer el mundo interior y exterior. Ahora bien la propia mente del experimentador puede conocer de dos modos: uno es la razón y la lógica, el otro modo es el holístico e intuitivo, dice García Ranz (1999, p.17), lo que nos refiere a la naturaleza de la filosofía perenne.

.Es así que la forma de conocer intuitiva es holística porque acorta la distancia entre el objeto observado y el observador porque al abrazar la totalidad no descompone ó divide. Lo que se traduce en una experiencia subjetiva, en donde lo que se busca es reducir la distancia entre el conocedor y lo conocido lo que resulta en el conocimiento intuitivo.

Al conocimiento intuitivo, que en las filosofías tradicionales se le conoce también como conocimiento trascendental porque trasciende a la persona para ir más allá de sí mismo y "perderse" en el otro; en el arte se le da muchos nombres: uno de los más comunes: inspiración, ha jugado un rol esencial dentro de cualquier tradición filosófica y en el vivir artístico ${ }^{35}$ (1999).

En el contexto de la pedagogía crítica esto implica aprender a sentir con los demás poniéndose en sus zapatos.

Por su parte, Arheim vincula a la percepción con la especificación y la generalización ya que aunque las considera paradójicas,dice : operan constantemente juntas dentro

35 García Ranz, 1999, pp.18-19 
del proceso unitario de la formación de imágenes (Arheim, 1993) ${ }^{36}$ así como también en la memoria y la formación de conceptos.

Por ejemplo con relación a la percepción visual, Arheim enfatiza que la visión es inseparable de la forma que tiene el organismo de afrontar las características relevantes de la realidad, esto opera arrancando de los aspectos más generales de las cosas y gradualmente avanza hacia imágenes tan específicas como lo requiera el propósito (Arheim, 1993). ${ }^{37}$

Un ejemplo de ello son los dibujos infantiles y el arte abstracto.

De esta forma se ha analizado aquí como la intuición es un aspecto fundamental para la percepción y cómo, en la medida que las personas desarrollan su intuición (inspiración según García Ranz) es posible acercarse a la naturaleza de las cosas aumentando el estado de conciencia sobre ellas, paso indispensable para plantearse la transformación de algo como propone la pedagogía crítica y fronteriza.

Por lo tanto se propone que las experiencias de enseñanza aprendizaje que se plantean para la educación artística en el país deberían estar dirigidas a fortalecer la intuición de los niños y las niñas por medio de experiencias de aprendizaje significativo que demanden la dinámica inseparable intuición - percepción en el sentido que proponen estos enfoques contemporáneos educativos.

\section{La Expresión}

R. Arheim y García Ranz coinciden en que la reflexión (meditación) es una condición para la expresión en las artes. Es decir la reflexión constituye un instrumento para obtener una dinámica perceptiva que permita conocer más allá de la objetividad, de manera que sea posible explorar la subjetividad en los procesos intuitivos implícitos en las artes.

La visión de Arheim que parte de la percepción-reflexión como base para la expresión en las artes es consistente 36 Arheim,1993, pp 31

37 Ibid. pp 33 con la de García Ranz, quien parte de la meditación, al describir la percepción como una dinámica que se expresa en tres aspectos ó virtudes que R. Arheim considera como los valores de la expresión artística:

Lo primero trata sobre lo que expresan las fuerzas físicas (por ejemplo, los elementos del viento, el agua y el fuego) presentadas a través del arte. En los diferentes lenguajes y objetos artísticos las fuerzas físicas tienen el potencial de revelar ó expresar las fuerzas de la mente.

Por ejemplo la atmósfera que se logra en un cuadro de Vermeer con el claroscuro y en donde casi se puede oír caer la leche en una vasija (Johannes Vermeer, La Lechera, 1658 - 60) lo que expresa además de una atmósfera objetiva una atmósfera subjetiva específica ó por ejemplo el viento en una escena teatral, en cine o en una instalación.

Esto constituye un importante potencial para la pedagogía crítica en el marco de la educación artística porque se traduce en el potencial de las artes para jalonar el imaginario de los educandos, moviéndolo de una lectura literal basada en lo objetual, concreto, hacia múltiples lecturas alternativas de los textos (contextos) (como lo propone Guiroux)

Los efectos, en los ejemplos mencionados, tienen la capacidad de comunicar algo más allá de la realidad concreta observable y ejemplifican la observación participante, cuando se trata del educando como espectador, y la posibilidad de diseñar esas lecturas alternativas cuando, el educando, participa como creador del hecho artístico en el contexto escolar. Dice Arheim que en el arte las fuerzas físicas representadas tienen la capacidad de representar además las fuerzas de la mente.

Lo segundo es la metáfora. Para Arheim el hecho fundamental que hay que comprender respecto al arte es que todo lo que muestra se presenta como un símbolo ${ }^{38}$

Lo que se dice en una obra teatral, lo que suena en una obra musical o se ve en el arte visual y cómo y en dónde se dicen los parlamentos de una obra, con qué y cómo se ejecutan las obras musicales y los trazos y materiales que

38 Arheim, 1993, pp. 47 
sirven de soporte físico a las obras visuales; tienen significado porque las obras artísticas estructuran un lenguaje metafórico y: ... (Las imágenes) apuntan a la naturaleza de la condición humana por medio de la dinámica de que son portadoras (Arheim,1999) ${ }^{39}$.

Para ello hay que comprender las cosas, los contextos y las realidades en profundidad, estos procesos a su vez, los facilitan los lenguajes artísticos.

Lo tercero trata sobre la resonancia ${ }^{40}$ que es sentir como el objeto observado, "ser" el objeto observado, diría García Ranz.

Por su parte Arheim lo describe así: ... La dinámica que transmite la imagen resuena en el sistema nervioso del receptor. El cuerpo del espectador reproduce las tensiones del balanceo, de la ascensión y de la inclinación de tal forma que él_mismo une en su interior las acciones que esta viendo realizarse en el exterior (Arheim,1999) ${ }^{41}$

Es así como no se puede divorciar el desarrollo del pensamiento crítico de la expresión artística - en su forma como lenguaje metafórico y de resonancia- lo cual esta asociado a la comprensión profunda de lo que nos rodea, condición importante para la formación de criterios que determinan nuestra reacción y actuar ante lo que se experimenta, ante lo que se vive.

De tal manera la expresión en la educación artística como se ha explicado es inseparable de la percepción - reflexión como condición previa para la creación, aún expresiones artísticas como el Automatismo y el Action Painting por ejemplo, parten de procesos de reflexión profundos sobre su razón de ser y de qué no ser. En su ejecución estas expresiones del arte y ejercicios de libertad en el ámbito disciplinar de las artes visuales tienen a la base la conciencia de las cosas, la meditación. Aquí se encuentra una posibilidad valiosa que brinda la educación artística para ensayar estas estrategias con el fin de conocer y profundizar sobre las cosas en los contextos cotidianos y para

39 Ibid, pp. 47

40 García Ranz también alude a este valor expresivo con relación a la dinámica perceptiva en el modo de conocer intuitivo.

41 Ibid, pp.47-48 llegar a comprender las estructuras sociales, políticas y culturales que las ordenan.

\section{Interpretación de la Cultura y el Mundo Natural}

Si como se dijo al principio, los componentes de la competencia en la Enseñanza por Competencias son: El saber, el saber hacer, el saber ser y convivir, con relación a la tercera competencia en la asignatura de Educación Artística que estipula el currículo nacional en El salvador, que es: Interpretación de la cultura y el mundo natural, esta competencia incluye saber sobre las diferentes manifestaciones culturales y artísticas de nuestro país de origen y el mundo, sobre la naturaleza, el medio ambiente y su importancia para la preservación de la vida en el planeta y su valor estético primordial para el crecimiento espiritual.

Al respecto dice Arheim que el ojo: ... es una parte de la mente. Para que la mente crezca, necesita contenido sobre el que reflexionar. Los sentidos, como parte de un todo cognitivo inseparable aportan ese contenido (E. Eisner,1999). ${ }^{42}$...La percepción y la representación son indispensables para captar propiedades esenciales del medio, se tienen que dar condiciones anormales para que esta admirable habilidad mental degenere en un simple copiar (Arheim,1993) ${ }^{43}$. Queda aquí implícita la importancia que Arheim confiere a la interpretación artística en el espacio escolar.

Por su parte, García Ranz aborda la interpretación partiendo de la intuición y la conciencia como condiciones para la creación.

Para la autora la intuición es lo que llamamos la inspiración en el proceso creativo en las artes. En este sentido dice García Ranz: "El origen del arte tiene lugar en virtud a la relación que se establece entre artista y la naturaleza" ${ }^{44}$ (García Ranz,1999).

De acuerdo a la Filosofía Perenne del Arte (basándose en las diferentes tradiciones artísticas) se dan jerarquías de grados de grandeza por los que atraviesan los artistas,

\footnotetext{
42 Opcit. E. Eisner citado en R. Arheim, pp15-16

43 Opcit. Arheim, pp35

44 Opcit. García Ranz, 1999, pp 98-99
} 
García Ranz describe estos niveles a partir de un primer grado que constituye la destreza necesaria para lograr la apariencia formal exterior de la naturaleza, el segundo es aquel en el que el artista es capaz de manifestar su propia energía expresiva. Estos dos, sin embargo, no son sino etapas previas dentro de la necesaria evolución del desarrollo artístico. El tercer grado corresponde al de un arte consolidado, pues en él, el artista ha podido plasmar una experiencia trascendental. Es de esta forma que podemos apreciar el rol primordial que juega la inspiración (García Ranz,1999) . ${ }^{45}$

Estos grados perceptivos y expresivos que describe la autora ilustran como a partir de la percepción dinámica, diría Arheim y la inspiración-intuición (García Ranz) se llega a la experiencia trascendental que ofrece el arte como forma de conocer y comprender el mundo siendo esto una condición previa para imaginarlo diferente, para cambiarlo.

La interpretación de la cultura y el mundo natural -como lo prescribe en la educación artística el currículo nacional en vigencia- debería ser precisamente el equivalente de la experiencia trascendental que plantea García Ranz, y el trascender la acción mecánica de copiar por medio de la observación activa, que discute R. Arheim, esta experiencia esta al alcance de los educandos por medio de la interpretación artística de las cosas.

Emulando -de acuerdo a su nivel de desarrollo biospicosocial- la manera de cómo los artistas están inmersos en el mundo:

Por un lado vemos que hay una propuesta original: la creación por definición es algo que no existía antes, pero por otro lado y reflexionando un momento advertimos que no hay nada nuevo estrictamente hablando. El arte y la creación humana no surgen de la nada (creatio exnihilo) como afirmaban los escolásticos, sino que "recrea" lo ya existente en una cierta configuración (García Ranz,1999). ${ }^{46}$

El pensamiento y la visión creadora del artista dependen de lo que existe en el mundo, del legado cultural de su 45 Ibid. pp99

46 Ibid, 1999, pp 174 época, de todo lo que ha producido el hombre a lo largo de los tiempos como son las formas, los objetos y lenguajes (García Ranz, 1999).47

Lo anterior implica que en la competencia: La interpretación de la cultura y el mundo natural, el saber hacer se traduce en el ensayo de los procesos cognitivos y el uso de las herramientas teóricas para aguzar la percepción dinámica frente a las manifestaciones culturales y el mundo natural. No desde una percepción pasiva, no crítica, sino basándose en la cada vez más profunda comprensión de las cosas que son y porqué son así, aspecto implicado en la pedagogía crítica, aspecto central de la pedagogía fronteriza, y elemento indispensable para interpretar el mundo.

También implica el diseño cuidadoso de experiencias de aprendizaje significativo en el área de la educación artística que garanticen, que los educandos, tengan experiencias con los diferentes lenguajes artísticos para expresar sus reflexiones sobre su vida, la cultura y la naturaleza por medio del discurso estético y para que experimenten el placer del disfrute de las artes, que es un valor implícito en la creación y apreciación participante del hecho artístico al que deberían tener derecho la niñez en todos los niveles socioeconómicos y culturas.

En cuanto a el saber ser y convivir la interpretación de la cultura y el mundo natural, implica el disfrute, la apreciación y participación en las artes, la cultura y en la apreciación y la preservación de la naturaleza. En este marco, los textos (discurso oficial, lo establecido) que se reproducen con relación a estos aspectos de la vida en el currículo, son productos históricos y éstos como expresiones de las estructuras sociales y culturales dominantes, constituyen una expresión tangible sobre los cuales reflexionar y a los cuales cuestionar mediante el discurso estético.

Al entender estos textos como:

[ ' ... construcciones históricas y sociales determinadas por el peso de lecturas heredadas y especificadas' (Giroux, 2000, p. 11). (Que) Los textos se pueden leer enfocán-

47 Ibid, 1999, pp174 
dose en la manera en que diferentes públicos pudieron responder a ellos, destacando así las posibilidades de leer contra, dentro y fuera de los límites establecidos] [González, 2007) ${ }^{48}$.

Esto para que los educandos vayan construyendo sus propias interpretaciones al confrontar estos textos (contextos) con sus conocimientos y experiencias, propiciando la negociación crítica de los límites culturales históricos que le ofrece la sociedad para proceder a transformar el mundo en que vive.

De esta manera lo anterior también contribuye a la construcción una actitud de aprecio a la creatividad implícita en la expresión de las ideas y tener la conciencia de la propia creatividad y el respeto a la de los otros, apertura y sentido crítico ante las diferentes culturas y sus manifestaciones artísticas.

De igual forma la apreciación de la cultura tiene el potencial de traducirse en la voluntad de crear y proteger el patrimonio natural y cultural de los pueblos, en la medida en que el educando les confiera sentido, se considere protagonista y que participe de su construcción y tutela en base al sentido que les da con relación a su vida cotidiana, para lo cual, tienen un papel central las artes en la sociedad y la educación artística en el currículo nacional.

Se ha profundizado hasta aquí en cada una de las competencias de la Educación Artística, porque en alguna medida, sus conceptos, constituyen ejes transversales en el desarrollo de esta asignatura en el currículo nacional y se han caracterizando cada una de estas competencias planteadas por el MINED, desde un rango conceptual amplio, a continuación, se presentan algunas reflexiones sobre el sentido que cobra la formación artística explorando los aspecto que coadyuvan a la vida del país, la formación de ciudadanía y la construcción social.

48 La Pedagogía Crítica de Henry A. Giroux. (Spanish)/ Martínez, Luis González._ Sinéctica; ago2006-ene2007 Issue 29, p83-87, 5p; Article; 1665-109X

\section{Valores artísticos para la construcción social.}

En cuanto a los objetivos de la Educación Artística en el currículo nacional y otros ámbitos formativos, en el contexto social salvadoreño, esto se relaciona con el sentido y funcionalidad del arte mismo dentro de la sociedad, cuya presencia en el currículo y otros espacios formativos se reflexiona a continuación.

El arte puede enseñarse en espacios de educación formal, no formal e informal, en estos espacios las posibilidades que conllevan las artes para el desarrollo humano y la construcción social son importantes. Esto se explica por la posibilidad que brindan las artes para el auto conocimiento, favoreciendo la construcción de identidad, la reflexión y aproximación crítica a los hechos de la vida propiciando una plataforma teórica, cognitiva y vivencial para favorecer los procesos de transformación, todo ello se facilita por el placer del disfrute de las artes como medio para conocer y conocerse. Así se demuestra en las experiencias y reflexiones siguientes.

El estudioso y crítico del arte salvadoreño, Luis Salazar Retana expresa que las artes inciden en cómo la gente se enfrenta con la vida. En este sentido se les puede atribuir la doble función de influenciar la vida de las personas desde la perspectiva de que en su dinámica, las artes contribuyen a que las personas sean más solidarias y sensibles por su naturaleza social, ya que promueven que sean conscientes de su entorno, y como hemos visto en este análisis, es parte del proceso de creación artística "ponerse en el lugar del otro", practicando la observación activa de la que habla R. Arheim y la observación subjetiva que plantea A. García Ranz frente a los fenómenos culturales, sociales y el entorno natural.

Las artes hacen posible, por ejemplo, que niños entre 6 y 12 años articulen de manera espontánea un discurso complejo, sobre las realidades socio económicas y ambientales del país a partir de un conversatorio con relación a una serie de fotografías del periódico local escogidas por ellos, para después pintar un mural con imaginería rica en metáforas, símbolos y realidades en donde ellos 
expresan lo que piensan y sienten sobre su país (Marta Eugenia Valle, 2007). ${ }^{49}$

En el marco del presente análisis vale la pena señalar, la altura de la conversación y los resultados plásticos que demuestran que los niños encuentran en las artes un medio de expresión privilegiado que favorece, en particular, hablar con libertad y en profundidad de sus sentimientos e ideas.

Esa experiencia se vuelve significativa y muestra el camino hacia la conciencia social, el libre pensamiento y la libre expresión.

Al mismo tiempo las artes posibilitan procesos cognitivos que conectan a las personas con su subjetividad, brindando la oportunidad de conocerse así mismos, en un proceso que implica aprender a ser conscientes de la propia creatividad, con ello se potencia la autoestima y se contribuye a construir la identidad individual que tendrá un impacto sobre la construcción de la identidad colectiva.

Ante la globalización una enseñanza del arte que haga reflexionar sobre lo que somos, sobre lo que poseemos, sobre nuestro ambiente, sobre las posibilidades artísticas de nuestro entorno, de nuestra manera de ser, de nuestra manera de pensar de como se puede intervenir en el arte universal (a partir de todo ello) ahí es donde la enseñanza del arte se vuelve poderosa (Luis Salazar Retana, 2007)

Las artes también brindan un espacio lúdico de diversión sana y esparcimiento_ dice Beatriz Nájera coordinadora del Departamento de Arte y Cultura de la Universidad Don Bosco. En ese departamento se trabaja con jóvenes en alto riesgo.

Y es que también, las artes potencian la auto-expresión, porque hace conscientes a las personas de la libertad de expresarse, por ello las artes brindan la oportunidad de re-crearse rompiendo los patrones monótonos de la rutina diaria.

La expresión artística, es parte del desarrollo humano. Ya sea como un espectador o protagonista es una parte

49 Taller infantil facilitado por Marta Eugenia Valle, Universidad Don Bosco para la realización de un mural para el Museo Tín Marín, El Salvador, 2001. fundamental en el desarrollo de la persona, los artista les enseñan a los espectadores nuevas dimensiones de cómo interpretar las cosas para no caer en un racionalismo cúbico... tener un nuevo sentido, una nueva perspectiva de lo que sucede y ha sucedido para que no sea solo el discurso lineal histórico, académico, sino que además se descubre una nueva faceta de las cosas (Oscar Picardo, 2007).50

Más allá de la disciplina artística que los niños están practicando, la actividad artística favorece el desarrollo de la capacidad reflexiva, por ello favorece la observación activa y el desarrollo de una actitud crítica ante la cultura y la naturaleza.

Las artes promueven la creatividad y el pensamiento innovador por lo que brindan también la posibilidad de generar opciones, el programa de Jóvenes Talentos en Letras que forma parte del Centro de Innovación Científica Tecnológica, Empresarial y Social de la Dirección de Proyección Social de la Universidad Dr. José Matías Delgado, dirigido a niños talentosos de escasos recursos económicos o en extrema pobreza es un programa sólido, que en el país demuestran el gran potencial de las artes para hacer la diferencia en la vida de la niñez, al impulsar el área de letras con escasa oferta académica en país, este programa iniciado en el 2005, ya esta dando sus frutos en las nuevas generaciones de escritores y comunicadores que de otra manera no hubieran tenido la oportunidad de dedicarse a ésas áreas de desempeño profesional debido a su estado de exclusión socio-económica.

Por su parte, Edwin López y Jorgelina Cerritos del Programa de Prevención Social Contra la violencia y la Delincuencia lo definen así:

El arte desarrolla la creatividad, la cual les sirve (a la niñez) para su vida, les ayuda a tener varias opciones, eso les ayuda a hacer su vida más fácil, (al desarrollar proyectos artísticos) aprenden a tener opciones, a buscar opciones, porque la idea es esa, cambiar las cosas. Por medio de la capacidad de representación gráfica expresiva (en el Programa) aprenden a expresar lo que sienten y piensan porque el dibujo y la pintura son para expresar ideas $y$ emociones (Edwin López, 2007)

50 Picardo, Oscar (Educador)2007, Entrevista. 
...por otra parte en las artes escénicas intentamos que los otros niños en sus dramas, escenas ó historias de títeres expresen posibles soluciones, lo que observan que podría mejorar, les ayuda a ser más propositivos. (Jorgelina Cerritos, 2007) ${ }^{51}$

Las artes presentan una valiosa oportunidad como instrumento para la construcción de una cultura de paz y de ciudadanía, la educadora Jorgelina Cerritos del Programa de Prevención Social contra la violencia lo resume:

El arte es una actividad que nos incita a la armonía, a vivir en equilibrio con los demás, a la solidaridad, a compartir el trabajo; por medio de las artes escénicas que son artes colectivas y también las artes plástica que son consideradas más individuales, el niño hace su dibujo pero esta expresando una realidad y por medio de ello esta en contacto con su entorno.

(En estos talleres) se promueve el compañerismo, se llega a comunidades muy conflictivas, después de siete meses ya hay un cambio positivo: niños en factores de riesgo, aprenden a recibir afecto, la confianza, el respeto basado en un diálogo y en una norma clara, creación de la conciencia individual y colectiva... Aquí las artes son un medio que por su naturaleza favorece el desarrollo humano de los niños y niñas del Programa (Jorgelina Cerritos, 2007) 52

\section{CONCLUSIONES}

Finalmente las artes construyen nuestra humanidad, como se ha visto, desde el análisis basado en R.Arheim (psicología gestalt y cognitiva) y Á. García Ranz (Filosofía Perenne del Arte), las artes son un instrumento poderoso para la formación de competencias que nos hacen crecer como humanos y sentirnos vivos.

De igual forma las competencias artísticas posibilitan el desarrollo humano en los valores para la construcción identitaria individual y colectiva, la construcción de una conciencia crítica sobre el entorno interior y exterior, así como la enseñanza artística por medio del desarrollo de los valores del arte contribuyen de manera específica a

51 López Edwin; Cerritos, Jorgelina (Educadores), 2007, Entrevista.

52 Cerritos, Jorgelina, 2007, entrevista. la construcción de ciudadanía, una cultura de paz y una sociedad solidaria.

Ahí radica la importancia de que en los contextos actuales las sociedades promuevan la enseñanza de las artes para todos y todas, que se formen maestros capacitados para ello.

Por lo tanto es importante que desde el Estado se revisen las políticas y el enfoque de la educación en general y en particular el de la Educación Artística para que por medio del disfrute del placer de las artes se favorezca una educación que lleve a la autonomía, el autoconocimiento, el pensamiento crítico que posibilite la formación de ciudadanía y el deseo de participar en los procesos de construcción social.

\section{REFERENCIAS}

Barbosa, A M: ( 2008) Preface. In: Eça, Teresa. \& Mason, R. (Eds) ( 2008). Intercultural Dialogues in Art Education. London: Intellect Books. ISBN : 978-1-84150-167-3

Martínez, Luis González. 2007_ La Pedagogía Crítica de Henry A. Giroux. (Spanish)/ Sinéctica; ago2006-ene Issue 29, p83-87, 5p; Article; 1665109X

Rudolf Arheim. , 1993. Consideraciones sobre la Educación Artística /— Barcelona: Ediciones Paidós Ibérica S.A-97p. : il. 21cm. — incluye índice. - ISBN 84-7509-877-0

El Currículo al Servicio del Aprendizaje: Aprendizaje por Competencias / Ministerio de Educación . - 2 $2^{\underline{a}}$ ed. - El Salvador: Ministerio de Educación, 2008 . - 56 p. : il ; 22 cm . - Incluye índice: ...

Ricardo Marín Viadel ... [et al] , 2008Didáctica de la Educación Artística para Primaria /._- Madrid : Pearson Education. - 317 p. : il. ; $21 \mathrm{~cm}$. Incluye índice. - ISBN 84-205- 3487-9

Ángeles García Ranz 1999. El Artista Interior/— México: Plaza y Valdéz editores,. - 209 p. : il. ; 20.5 cm . - Incluye índice . - ISBN 968-956$687-\mathrm{X}$

César Coll... [et al.] , 1992 Los contenidos en la Reforma: enseñanza y aprendizaje de conceptos, procedimientos y actitudes /.- Madrid : Santillana.— 202 p. : gráf. ; 21 cm .— Incluye índice .— ISBN: 8429435891

\section{Recursos digitales}

Una Aproximación metodológica Interdisciplinaria en la Educación Artística [Recurso electrónico] / Humberto Chávez Mayol . — Discurso Visual [Revista digital] . - Nueva época, n. 7 (Septiembre-Diciembre, 2006)- . - [México?] : Cenidiap, 2006 . - Revista digital : http://www. cenidiap.net . - Modo de acceso: World Wide Web. - Descripción 
basada en n.7 (2006), consultado en Abril 2008 . — Irregular. — ISSN 1870- 3429

Los Claroscuros de la Educación Basada en Competencias [Recurso electrónico] / Carlos Jesús Guzmán . - Nueva Antropología, Revista de Ciencias Sociales, [Reproducción en PDF] . - N. 62, (Abril, 2003) .- México : Asociación Nueva Antropología, A. C, 2003 http://www. juridicas.unam.mx/publica/rev/indice.htm?r=nuant\&n=62. - Modo de acceso: World Wide Web. - Descripción basada en n. 62 (2003), consultado en abril 2008 . - Cuatrimestral. — ISSN 0185-0636.

Global Competencies for Future- Ready Students [ Página Web] :What North Carolina High School Graduates need to thrive in the global economy / Suárez-Orozco M. ; Sattin, Carolyn . — [ North Carolina?] : Global Center for International Understanding ; Association for Supervision and Curriculum development, 2008.

Descripción basada en PDF

Programas de Estudio de $1^{\circ}$ a $6^{\circ}$ grado [Página Web] . - / Ministerio de Educación . - El Salvador: Ministerio de Educación de El Salvador, 2009 